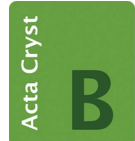

STRUCTURAL SCIENCE CRYSTAL ENGINEERING MATERIALS

ISSN 2052-5206

Keywords: book review; intermetallics

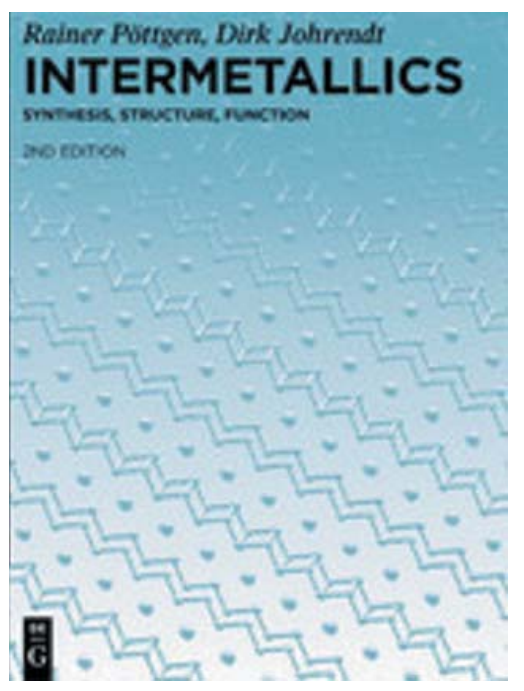

C 2019 International Union of Crystallography

\section{Intermetallics. Synthesis, Structure, Function. Second edition. By Rainer Pöttgen and Dirk Johrendt. De Gruyter, 2019. Paperback, $x+314$ pp. Price EUR 64.95, USD 74.99, GBP 59.00. ISBN 978-3-11-063580-5.}

\author{
Walter Steurer*
}

Loorenstrasse 60, Zurich, CH-8053, Switzerland. *Correspondence e-mail: walter.steurer@mat.ethz.ch

Why should I read this book? I thought we were living in the Plastic Age? Is not all I need to know as a chemist/materials scientist what I can do with elements such as $\mathrm{C}, \mathrm{H}, \mathrm{N}, \mathrm{O}$ etc? No, definitely not. You should know what you can do with the metallic elements as well, which comprise more than $80 \%$ of the periodic table. You should get an idea about what intermetallic phases are and which properties they have. You should enter the fascinating world of structures of intermetallic phases emerging from non-directional metallic bonding. The present book will introduce you as a student or newcomer to this exciting field.

A book from chemists to chemists - this is a short summary of the book. The target group are Master and PhD students with the focus on solid state chemistry. Five years after the successful first edition, the second edition has appeared now as paperback at a price which is also affordable for students. Not much was changed in the new edition, just that Chapter 2 Synthesis and Chapter 4 Function have been given more space.

What is the structure of this book? There are just over 300 pages filled with the four chapters: Chapter 1 Introduction contains a one-page overview of the content and a short list of references for further reading. Chapter 2 Synthesis, presents 44 pages, in an introductory way, all common techniques for the synthesis of intermetallic phases. After each subchapter, a list of references points to sources for more detailed explanations and practical applications of these techniques is given.

The main part of this book, Chapter 3 Structure, deals with a discussion of the crystal structures of metallic elements and compounds. The point of view is clearly that of a solid state chemist rather than that of a crystallographer. This means that crystallographic information is sparse: no extensive symmetry information or Pearson symbols are given. Each subchapter deals with a main group '-ide', such as aluminides, gallides, indides, aurides and platinides, etc. Of course, important groups of intermetallic phases such as the Hume-Rothery or Laves phases are discussed as well. The final chapter (Function) is devoted to functional intermetallics as well as to nanomaterials and metallic glasses. The book closes with extensive formula and subject indices, respectively. However, one is lost if one does not have the chemical intuition on the arrangement of elements in a chemical sum formula. For instance, where would you look for the case of an intermetallic with composition 1:2:1 in the system Al-Cu-Mn? $\mathrm{Cu}_{2} \mathrm{MnAl}$, of course; or, another example, would you have correctly searched for $\mathrm{Ba}_{4} \mathrm{SiAs}_{4}$ ? It would provide easier access to the correct page if the elements were to be arranged in alphabetical order. Such a formula index could be added. Since the book targets students, exercises after each subchapter would have been helpful. But, perhaps, all this is already planned for the third edition. 